\title{
How Do IT-related Traits Drive the Internet Use of Mature Adults? The Interplay of Curiosity and Control
}

\author{
Robert Rockmann \\ Neu-Ulm University of Applied Sciences \\ Center for Research on Service Sciences (CROSS) \\ robert.rockmann@hs-neu-ulm.de
}

\author{
Heiko Gewald \\ Neu-Ulm University of Applied Sciences \\ Center for Research on Service Sciences (CROSS) \\ heiko.gewald@hs-neu-ulm.de
}

\begin{abstract}
It can frequently be observed that mature adults use the Internet differently as younger members of society. We propose a model based on IT-related traits to conceptualize the Internet use behavior of mature adults, specifically focusing on curiosity-and control-related traits. We empirically tested our model by investigating the duration and intensity of mature adults' Internet use. The results reveal that traits reflecting 'curiosity' (Personal Innovativeness in IT and Computer Playfulness) explain variations in the duration of Internet use, while traits reflecting 'control' (Computer Self-Efficacy and Computer Anxiety) predict the intensity to which mature adults make use of the Internet. Our paper thereby contributes to research on post-acceptance variations and on individual differences in IT use.
\end{abstract}

\section{Introduction}

The Internet has evolved as a ubiquitous and powerful medium for our entire society which literally changed the way we live [1]. For private individuals, the Internet offers a broad spectrum of capabilities and features like access to information, communication through email or social networks, buying products or services through e-commerce platforms, etc. Despite the many advantages the Internet offers, age-related differences in the utilization of the Internet can be frequently observed $[1,2]$. Whilst today's young people who grew up with the Internet ('digital natives') are often regarded as technology-savvy making full use of its available features [3], mature adults, on the contrary, became exposed to digital technologies during their adult lifetime ('digital immigrants') and are often assumed to pose resistance towards technologies or to struggle in their usage of them $[3,4,5]$.
This target group -here defined as aged 50 and above [2]- is frequently reported to use the Internet less often and underutilizing the potential to enhance their quality of life [1]. However, this dominant perspective about mature adults' technology utilization became criticized as scholars acknowledged that the target group's technology use is by far more heterogeneous than often assumed [1]. Thus, it becomes important to identify the factors that can unravel this heterogeneity in mature adults' technology use.

In information systems (IS) research, especially IT-related traits are positioned to enhance the understanding about individual differences in technology use. These traits cover the established factors Computer Self-Efficacy, Computer Anxiety, Personal Innovativeness in IT, and Computer Playfulness [6]. Although research has shown that these traits can be influential for individual's technology use in general, little is known whether ITrelated traits can promote different usage behaviors.

Descriptive studies about mature adults' Internet use behavior is often reported in terms of Internet use duration (time spent using the Internet) and Internet use intensity (the use of multiple options the Internet offers, like information retrieval, communication, etc.) $[7,8,9]$. Information systems scholars are aware that these commonly employed conceptualizations denote different aspects of technology 'use' [10] and preliminary evidence indicates that such different forms of 'use' can be predicted differently $[11,12]$.

However, little is known whether IT-related traits may also exhibit different effects on different conceptualizations of 'use'. Thus, our research asks the broader question: Do IT-related traits predict different types of technology use (duration vs. intensity) by mature adults?

We aim to contribute to the literature on mature adults' interaction with technology and thus choose our research objects from this age group since certain traits like computer self-efficacy and computer anxiety are regard as important factors of this 
audience $[1,7,13]$. Thus, our research explores whether frequently employed IT-related traits can have differing effects on two common conceptualizations of 'use' -duration and intensityin the context of mature adults' Internet usage.

We propose an alternative conceptualization of the established IT-related traits by distinguishing between 'curiosity' and 'control' related traits: whilst Personal Innovativeness in IT and Computer Playfulness resonate with 'curiosity', Computer SelfEfficacy and Computer Anxiety reflect aspects of 'control'. In the following, we develop arguments how these curiosity- and control-related traits can predict usage duration and usage intensity, which we analyze in a simultaneous manner to examine which traits are able to predict distinct usage behaviors. We test our model using survey data of mature adults aged 50 and above.

Our research addresses two shortcomings of prior research. First, despite few exceptions [14], most research assessed only one or two of these traits and not the full set of all four established traits thereby limiting our understanding about possible interrelations amongst these traits. Second, the different conceptualizations of 'use' frequently investigated depict different aspects, such as time spent or features used. Though prior research has shown that IT-related traits can pose effects on the conceptualizations of use employed, little is known whether certain IT-related traits may have differential influences on these forms of usages.

As such, our research contributes to research and practice by 1) refining our understanding of ITrelated traits and their effects on different types of use, and 2) by explaining individual differences in mature adults' Internet use.

The paper is structured as follows. In the next section, we outline prior research on conceptualizations of IT-related traits and how they predicted various kinds of use. We then propose our conceptualization and develop our hypotheses exploring whether IT-related traits predict different types of Internet use. After that, we outline our research methodology. Building on the findings gained through our empirical investigation, we discuss our findings, highlight implications, discuss the study's limitations and close with the conclusion.

\section{Literature review}

Individual differences have been extensively investigated as important predictors of technology acceptance and use [4, 15]. Despite basic demographic variables such as gender, age or education, especially IT-related traits were found to be helpful in explaining technology related behavior $[6,16]$. In the following sections, we first introduce these four traits, their origins and nature, as well as their influence on technology-related use behavior. Then, we propose our alternative conceptualization of these traits which we classify as either 'curiosity' and 'control' related traits.

\subsection{IT-related traits}

Individual differences have been extensively investigated as important predictors of technology acceptance and use [4, 15]. Despite basic demographic variables such as gender, age or education, especially IT-related traits were found to be helpful in explaining technology related behavior $[6,16]$. These IT-related traits commonly involve Computer Self-Efficacy, Computer Anxiety, Personal Innovativeness in IT, and Computer Playfulness [6].

The traits differ in their theoretical origins from behavior theories, such as Social Cognitive Theory [17, 18], Diffusion of Innovations [19, 20] or other personality theories [21, 22]. Prior research generally employed these individual factors with different lines of argumentations. Whilst one stream argued about the effects of these factors with their corresponding theoretical origins, another stream investigated those from a trait hierarchy perspective where IT-related traits are argued to be domain-specific instances of higher order personality traits such as the 'big five' personality traits [6].

The traits are briefly outlined and defined in the following paragraphs.

Computer Playfulness (CP) is "the degree of cognitive spontaneity in microcomputer interactions" [21, p. 204]. This IT-specific trait originated out of one's general cognitive playfulness -or 'autotelic personality' [22]- and reflects one's "tendency to interact spontaneously, inventively, and imaginatively with microcomputers" [21, p. 202]. CP is considered as an intrinsic motivation to use computers as is reflects the "openness to the process of using systems" [23, p. 348]. Accordingly, prior research has found CP to be influential in peoples' technology-related cognitions as well as actual use behaviors. For instance, $\mathrm{CP}$ is related to positive attitudes towards using computers, higher computer self-efficacy, lower computer anxiety [21], and positive easy-of-use perceptions [23]. As a result, CP not only contributes to individuals' willingness to use IT [23, 24], but also directly affects the actual usage behavior where $\mathrm{CP}$ leads to deep involvement while using IT (i.e. 'cognitive absorption') [25].

Personal Innovativeness in IT (PIIT) denotes "the willingness of an individual to try out any new 
information technology" [26, p. 206]. Rooted in innovation diffusion theory $[19,20]$, PIIT is a domain-specific derivate of an individual's broad personality trait 'openness to experience' [27] that increases the willingness to change and to take risks [28]. Innovative individuals develop positive attitudes towards new technologies, engage in innovative behavior and are often considered as 'early adopters' of new technologies [4, 15, 26]. Individuals with high PIIT often possess higher computer self-efficacy and lower anxiety towards IT [16]. They develop positive perceptions of the technology's ease-of-use and usefulness [26, 29, 30]. PIIT therefore influences actual technology usage as it promotes novel and innovative uses of technology [31] where people employ more and new features [14, 32, 33, 34]. Like CP, PIIT amplifies deeper involvement with a focal technology [25].

Computer self-efficacy (CSE) is defined as the “judgment of one's capability to use a computer" [35, p. 192]. CSE originated from Social Cognitive Theory [17, 18] where general self-efficacy reflects "the belief in one's capability to organize and execute the courses of action required to manage prospective situations" [17, p. 2]. Self-efficacy acts as a key determinant of behavioral control [17] and became incorporated into the Theory of Planned Behavior by reflecting internal control beliefs [36]. Not surprisingly, a vast amount of IS research reports the important role of CSE for IS-related cognitions and behavior [16, 18, 23, 37]. For instance, individuals high in CSE perceive IT as more easy to use and as more useful [25] which increases their intention to use or to continue using a technology $[38,39]$ and the likelihood that individuals engage in innovative use especially of complex IT [31]. In terms of actual use, Compeau et al. [18] reported that CSE directly determines the duration and frequency of technology use, whilst Davis and Mun [14] revealed that CSE predicts the extent to which individuals utilize the Internet for online-shopping or social networks.

Computer Anxiety (CA) reflects the tendency of individuals to be uneasy, apprehensive or fearful when confronted with using computers. The fear to produce data losses and/or other (irreversible) mistakes [40, 41]. CA is determined by one's general trait of neuroticism [27] and general anxiety [16]. Individuals with high computer anxiety often possess feelings of helplessness [42], perceive IT as less easy to use $[23,24]$ and pose decreased self-beliefs in their ability to use a computer [16, 35].

In sum, these four traits were shown to deliver dependable results as individual differentiators in ITrelated studies. Moreover, these traits are not only important during the pre-acceptance phase, but also in the post-acceptance phase where these traits affect various usage behaviors such as duration and frequency of using a technology [18], applying a technology for different purposes (e.g. using the Internet for commerce or social networks) [14], exploring new purposes and features [31], or becoming deeply absorbed when using IT [25].

\subsection{Mature adults' use of technology}

Mature adults tend to adhere to familiar and traditional media practices, rather than making intense use of the digital environment [43]. However, studies indicate that whilst some mature adults do not perceive themselves being able to make use of technologies and experience feelings of apprehension and helplessness, others pose high confidence in their abilities and have less anxious feelings when it comes to interacting with technology $[5,7,42]$. The sense of (not) being in 'control' of the technology resonates in both cases either as an enabler or inhibitor of technology-related behavior [44]. On the other hand, some mature adults state that they are simply not interested in technologies, whilst others are eager to explore the various facets the Internet provides $[2,7$, 45]. Here, a sense of 'curiosity' reflecting interest and motivation to discover IT reverberates [46].

Altogether, research on the specifics of mature adults use of technologies is rather scarce, indicating an important research opportunity [5]. Though preliminary research on mature adults' Internet use indicates that certain IT-related traits -especially computer self-efficacy and computer anxiety [1, 13]can act as important individual factors, a deeper understanding about individual differences and their impact on mature adult's Internet use is needed.

In the following we describe our model to investigate two alternatively conceptualized traits and their power to predict mature adults Internet use.

\section{Research model}

After careful examination of the IT-related traits described above, we noticed that these factors resonate with notions of 'curiosity' and 'control' that may impact mature adults' Internet use.

Curiosity is a motivated desire for information or intrinsic motivation to explore novel situations [46]. Curiosity is seen as an individual's response to novel stimuli that trigger emotional states of uncertainty but equally motivate the individual towards exploration and acquisition of new information [47, 48]. Curiosity is frequently associated with positive affectivities of pleasure and enjoyment; curiosity induces exploratory behavior to acquire new 
knowledge which, in turn, leads to intrinsic rewards and pleasure [47, 49]. Both, Personal Innovativeness in IT and Computer Playfulness have a common grounding in the desire for exploration [14, 23, 50] and thus reflect curiosity.

Control, in contrast, is considered as a situational enabler or inhibitor of behavior [44] that reflects one's perception of the availability of resources and knowledge needed to perform a distinct behavior and that consequently determines key variables like intention and behavior [51]. Computer Self-Efficacy and Computer Anxiety echo such judgments and feelings of control.

In the following sections, we develop arguments how control and curiosity may drive different usage behaviors. A graphical representation of our research model is depicted in Figure 1 later on in this paper.

\subsection{Internet use: duration and intensity}

Post-adoption research informs how a given technology is used after its initial introduction [10, 52]. Actual technology use is often conceptualized and reported with a temporal dimension related to duration or frequency $[10,11]$. Another frequently employed measure involves the use of the 'features' provided by the technology $[10,52]$. Both conceptualizations denote different aspects and therefore may be differently predicted:

Internet Use Duration is defined as the average amount of time an individual spends using the Internet per week [adapted from 11].

Internet Use Intensity, is defined as the absolute number of Internet features an individual uses [based on 53]. For our study, these features include the following typical activities: information seeking, reading news, buying products, online banking, communication (email, chat or internet-calls), entertainment (videos or games), or general 'Internet browsing' [53].

We assess these two measures simultaneously $[11,12]$ in order to reveal whether certain traits are better predictors for either duration or intensity. Corresponding arguments are developed within the next sections.

\subsection{Curiosity-related traits}

We suggest that Personal Innovativeness in IT (PIIT) and Computer Playfulness (CP) both depict facets of curiosity. As illustrated above, the two factors reflect intrinsic interest and motivations, desires, as well as openness towards exploring and using IT [21, 26, 32]. As curiosity and creativity are considered as the common roots of both traits [14], we first establish a link between these traits in order to ensure that both factors are related to 'curiosity'.

Hereto, Davis and Mun [14] argue and provide evidence from the trait-hierarchy perspective, that the innovativeness characterizing individuals high in PIIT promote the spontaneous and creative usage behavior reflected by $\mathrm{CP}$. Thus, we posit:

\section{H1: PIIT has a positive effect on CP.}

Intrinsic motivations are the strongest predictors for the time spent on an activity [11, 23, 54, 55]. Both, PIIT and CP reflect an individual's internal motivations to use and explore technologies and are strong predictors of cognitive absorption or flow in IT usage [25]. Cognitive absorption is a feeling of sensation when acting with total involvement [22] or the experience of becoming absorbed in an activity. This experience is multidimensional as it involves concepts such as temporal dissociation, attention focus, intrinsic enjoyment and curiosity [22, 25]. When people encounter this state of flow, they become unaware of the time spent in an interaction [25]. Moreover, it has been shown, that curiosity can increase the enjoyment of using IT [49], which in turn captures the intrinsic motivation in a flow experience [25]. Curiosity can induce exploratory IT behavior that in turn promotes higher temporal engagement in activities [21]. Additionally, it is argued that cognitively absorbed people tend to spend more time on the Internet [56]. Thus, we hypothesize:

\section{H2: PIIT has a positive effect on Use Duration.}

H3: CP has a positive effect on Use Duration.

Despite the arguments regarding the relationship between curiosity and use duration, prior literature reported that PIIT and $\mathrm{CP}$ also affect use intensity. However, a notable difference can be seen in the arguments research has provided on these effects. For instance, a common line of argumentation is that individuals high in PIIT have a higher propensity to take risks when confronted with novel IT [23, 26]. Thus, it has been shown that people high in PIIT and $\mathrm{CP}$ possess positive beliefs about their abilities to use IT (i.e., computer self-efficacy) [16, 21] equally perceive IT as more easy to use rendering it as less complex [23, 24, 29]. Thus, the reasoning of prior research about the influence of PIIT and $\mathrm{CP}$ on use intensity is rather based on abilities than on curiosity and creativity. Partial empirical support for our observation is provided by Davis and Mun [14]. The authors investigated the influence of all four ITrelated traits on web utilization, a composite measure involving the various functionalities used from the Web that reflects use intensity. The results indicate that in the presence of computer self-efficacy and 
computer anxiety, PIIT does not pose direct effects on web utilization. However, in order to explore whether PIIT and CP can equally pose effects on use intensity, we also hypothesize:

\section{H4: CP has a positive effect on Use Intensity.} H5: PIIT has a positive effect on Use Intensity.

\subsection{Control-related traits}

Prior research frequently highlighted the importance of control-related traits in the realm of mature adults where CSE, for instance, has been found to be a key predictor of their Internet acceptance and use $[1,13]$ though CSE decreases and CA increases with higher age [27].

Behavioral control perceptions strongly determine actual behavior [44]. As outlined, CSE and CA can be seen as two concepts reflecting control. Thus, we first establish a link between these two traits in order to give support for their nature of 'control'.

According to Social Cognitive Theory [17, 57], emotional arousal, such as anxiety, and self-efficacy are reciprocally determined depending upon which factor serves as stimuli [23]. Therefore, the negative relationships between CSE and CA have been found in both causal directions $[16,18,58]$. As CSE might act as an important coping mechanism in dealing with negative emotions of having no control over a technology [24], we hypothesize:

\section{H6: CSE has a negative effect on CA.}

Next, we argue that these control-related traits can result in different technology usages beginning with Internet Use Intensity. Social Cognitive Theory [17, 57] informs that individuals regulate their behavior according to their evaluations of their own capabilities [17]. The Internet offers a multitude of functionalities ranging from rather simple interactions such as browsing and information seeking to more sophisticated functionalities such as online shopping or online banking [59]. As such the Internet offers varying degrees of complexity. Complex IT can pose a cognitive obstacle to individuals and CSE is argued to be a cognitive resource that enables individuals to cope with complex IT [31]. Accordingly, Internet functionalities with greater complexity are argued to require higher levels of CSE [59]. In that respect, Davis and Mun [14] revealed that CA and CSE predict the extent to which individuals utilize the various functionalities of the Internet such as online shopping or social networks. Accordingly, we posit:

H7: CSE has a positive effect on Use Intensity.

\section{H8: CA has a negative effect on Use Intensity.}

Despite our key contention that control-related beliefs become more pronounced when observing use intensity, prior research also found these traits to be related to use durations. Individuals high in general self-efficacy have been reported to be more committed in achieving goals and to be more active in information searching [31]. This might lead to spending more time on an activity. Compeau et al. [18] report that individuals with high CSE use a given technology longer and more frequently, reflecting a temporal dimension of actual use. In line with reciprocal mechanisms of $\mathrm{CSE}$ and $\mathrm{CA}$, we suggest that both factors determine Internet use duration and hypothesize:

H9: CSE has a positive effect on Use Duration. H10: CA has a negative effect on Use Duration.

\section{Research methodology}

\subsection{Data collection}

To test our model, we employed a quantitative survey. The questionnaire utilized measurement items drawn from the corresponding constructs. All items were translated to German and, if necessary, adapted to the Internet context. PIIT was measured by 4 items taken from Agarwal and Prasad [26] and adapted to the Internet context. CP was measured by 4 items of [25] who already adapted the original measure [21] to the Internet context. CSE was measured by 5 items $[37,60]$ based on the original CSE scale [35]. CA was measured using 4 items taken from [35]. All latent constructs are measured reflective on a 7-point scale anchored from 'strongly disagree' to 'strongly agree'. Only CSE was measured on a 10-point scale from 'not at all confident' to 'totally confident' as per the original scale [35]. Moreover, we measured Internet Use Duration as the average amount of time a person spends using the Internet in a typical week. Respondents answered on 7 points ranging from 'not at all', 'less than 1 hour', ' $1-5$ hours' up to 'more than 30 hours'. Measures for Internet Use Intensity are derived from [53], where respondents ticked off the Internet functionalities they use: seeking for information, reading news, buying products, online banking, communication (email, chat or telephony), entertainment (videos or games), or browsing [53]. Based on these binary values, a total score of Internet use intensity ranging from 1 to 7 was calculated [53].

We validated the instrument with 18 respondents from the target group to ensure readability, 
Table 2. Ps ychometric properties of the meas urement model

\begin{tabular}{|c|c|c|c|c|c|c|c|c|c|c|c|c|}
\hline \multirow[b]{2}{*}{ \# } & \multirow[b]{2}{*}{ Construct } & \multirow[b]{2}{*}{ Items } & \multirow[b]{2}{*}{ Loadings } & \multirow[b]{2}{*}{ AVE } & \multirow[b]{2}{*}{ CR } & \multirow[b]{2}{*}{ CA } & \multicolumn{6}{|c|}{ Discriminant validity } \\
\hline & & & & & & & 1 & 2 & 3 & 4 & 5 & 6 \\
\hline 1 & $\mathrm{CA}$ & 5 & $0.706-0.842 * * *$ & 0.606 & 0.885 & 0.838 & 0.779 & & & & & \\
\hline 2 & CSE & 5 & $0.779-0.875 * * *$ & 0.693 & 0.918 & 0.889 & -0.286 & 0.832 & & & & \\
\hline 3 & PIIT & 3 & $0.811-0.897 * * *$ & 0.753 & 0.901 & 0.837 & -0.177 & 0.243 & 0.868 & & & \\
\hline 4 & $\mathrm{CP}$ & 4 & $0.818-0.874$ *** & 0.718 & 0.911 & 0.871 & -0.188 & 0.351 & 0.343 & 0.847 & & \\
\hline 5 & Duration & 1 & $1.000 * * *$ & 1.000 & 1.000 & 1.000 & -0.344 & 0.108 & 0.271 & 0.276 & 1.000 & \\
\hline 6 & Intensity & 1 & $1.000 * * *$ & 1.000 & 1.000 & 1.000 & -0.424 & 0.316 & 0.197 & 0.213 & 0.354 & 1.000 \\
\hline
\end{tabular}

comprehensibility and proper wording before carrying out the survey. After that, we employed a field survey approach in the southern part of Germany by randomly asking people to participate in the survey at different locations such as train stations, libraries, gyms, adult schools, or senior citizen centers. Three independent research assistants carried out the survey. All potential respondents have been ensured for data confidentiality and that there are no wrong or right answers for the survey. Respondents have been incentivized with the chance to win a tablet computer. In total, we received 165 surveys, dropped 30 response sets due to incomplete data or respondents age below 50 years, and analyzed our hypotheses based on the remaining 135 surveys. The demographics are reported in Table 1.

Table 1. Sample demographics

\begin{tabular}{|c|c|c|c|c|c|}
\hline \multicolumn{2}{|c|}{ Age } & \multicolumn{2}{|c|}{ Gender } & \multicolumn{2}{|c|}{ Marital status } \\
\hline 50 's & $22 \%$ & Male & $34 \%$ & Single & $11 \%$ \\
\hline 60's & $44 \%$ & Female & $66 \%$ & Married & $66 \%$ \\
\hline 70 's & $27 \%$ & \multicolumn{2}{|l|}{ Retired } & Divorced & $8 \%$ \\
\hline \multirow[t]{2}{*}{80 's } & $6 \%$ & Yes & $67 \%$ & Widowed & $14 \%$ \\
\hline & & No & $33 \%$ & Other & $1 \%$ \\
\hline \multicolumn{6}{|c|}{ Household income (in Euro) } \\
\hline$<1 k$ & $1 \%$ & $3-4$ & 239 & n.a. & $15 \%$ \\
\hline $1-2 k$ & $20 \%$ & $4-5$ & $7 \%$ & & \\
\hline $2-3 k$ & $24 \%$ & $>5$ & $10 \%$ & & \\
\hline
\end{tabular}

\subsection{Data analysis}

We analyzed the data using partial least squares based structural equation modeling (PLS-SEM) with the software SmartPLS 3.0 [61]. We followed the established two-step procedure as per Chin [62]: we first analyzed the measurement model and the structural model in the second step.

As depicted in Table 2, we found satisfactory support for reliability and validity of the employed measurement model. Indicator reliability requires item loadings above 0.707 and to be significant [62]. The reverse phrased item of the four items in PIIT was therefore dropped (loading 0.428). One item of CA was with a significant loading of 0.706 at the edge of the threshold and kept within the analysis. Thus, all employed items are significant and loaded between 0.706 and 0.897 . Construct reliability values for Cronbach's Alpha (CA) and Composite Reliability (CR) are between 0.837 and 0.918 surpassing the required threshold of 0.707 [62]. Values for Average Variance Extracted (AVE) are between 0.606 and 0.753 and exceed the required threshold of 0.5 [63]. Discriminant validity is supported as that construct correlations are smaller than the square root of AVE [63]. Given the adequate properties of the measurement model, we proceeded to analyze the structural model and its hypotheses.

To this end, we assessed the coefficients of determination $\left(\mathrm{R}^{2}\right)$ and the significance levels of the path coefficients [62]. As illustrated in Figure 1, for our two dependent variables, $19.4 \%$ of variance in Internet use duration, and $23.1 \%$ of the variance in Internet use intensity can be explained by the four constructs that represent individual differences.

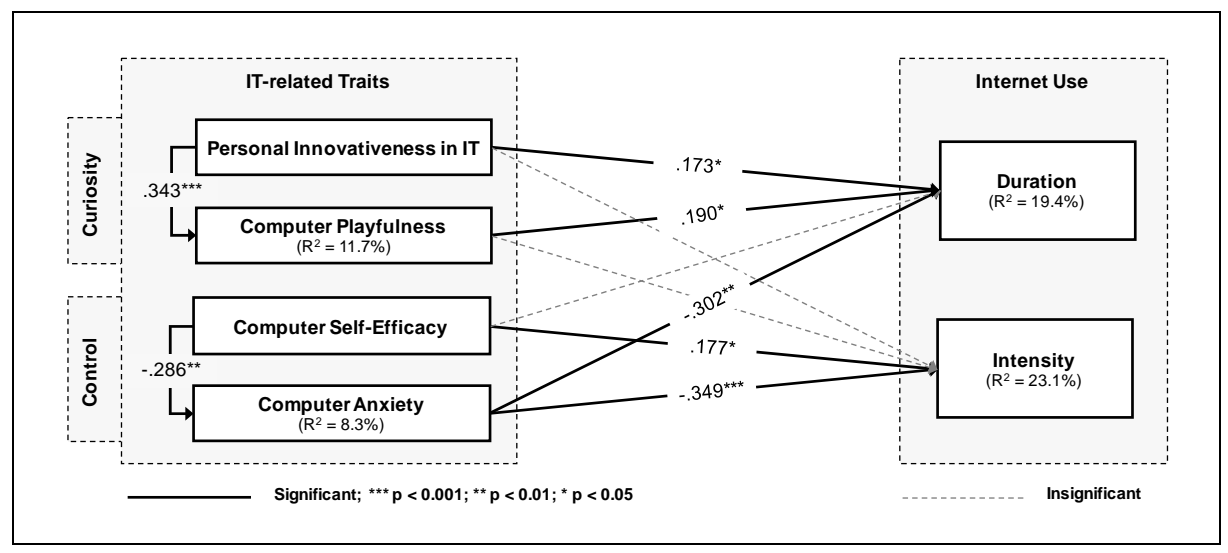

Figure 1. Res ults of the structural model 
We further controlled for effects of gender and age on both Internet Use variables. We observed neither effects of age on duration $(-0.046 ; \mathrm{p}=0.593)$ nor on intensity $(-1.04 ; \mathrm{p}=0.183)$. Similar, no effects of gender on duration $(0.006 ; \mathrm{p}=0.950)$ and on intensity $(-0.026 ; \mathrm{p}=0.755)$ occurred.

\section{Discussion}

The results of our empirical data demonstrate that IT-related traits account for about $19 \%$ of the variance in Internet use duration and for about $23 \%$ of the variance in Internet use intensity. Although these values seem small, the results correspond with recent research that solely relied on these variables in explaining Internet use with a reported $\mathrm{R}^{2}$ value of $25 \%$ [14]. In our research, seven out of the ten hypotheses that argue how these traits predict duration and intensity of Internet use are supported.

Our empirical data supports the underlying assumptions that PIIT and CP share a common facet of 'curiosity' and CSE and CA, in contrast, are equally related with each other as a 'control' facet.

It was most interesting to find that curiosityrelated traits (PIIT and CA) are the best predictors for Internet use duration, whereas control-related traits (CSE and CA) better predict Internet use intensity (although CA poses comparable effects on Internet use duration). As such, our results underline the validity of the general assumption that curiosity and control drive distinct usage behavior.

\subsection{Contribution to research}

Our research provides contribution to postacceptance research. To the best of our knowledge, there are only two studies that examine such differential effects of factors predicting different conceptualizations of system use. Venkatesh et al. [11] examine how behavioral expectation, facilitating conditions, and behavioral intention exert different effects on duration, frequency, and duration. In contrast, Lallmahomed et al. [12] reveal how factors of the unified theory of acceptance and use of technology exert differential relationships with Cognitive Absorption, Deep Structure Use, as well as with volume, frequency, and intensity use measures.

In contrast to these studies, we examined the notion of individual differences and how these affect duration and intensity of Internet use. Prior research on these IT-related traits has found sometimes mixed effects; one reason for the difficulty to compare and relate these results from many studies can grounded in the fact, that system use has been conceptualized in different manner. It has been criticized that researchers often study system usage without explicit arguments that justify the kind of usage being measured [10]. In line with [11] and [12], we contribute to our understanding that IT-related traits likewise predict different types of system use. However, by offering a novel approach of conceptualization in terms of curiosity and control, there are underlying cues that contribute to our understanding why corresponding factors predict different use types.

Our results indicate that both IT-traits related to 'curiosity' (PIIT and CP) are better predictors of use duration than use intensity. As outlined above, prior research often explained the influence of PIIT and CP on use intensity with arguments that rather reflect the control-related aspects than with curiosity-related arguments. Our results suggest that a curiosity perspective provides better accounts for duration rather than intensity. Both factors reflect intrinsic interest and motivations, desires, as well as openness towards exploring and using IT [21, 26, 32]. Individuals who are highly intrinsically motivated tend to spent higher amounts of time [11, 23, 54, 55]; they become 'absorbed' in their activities [22] and thereby unaware of the time spent [25]. However, little is consequently known in which activities these individuals actually engage when spending more time on using the Internet. A potential explanation might be borrowed from Mcelroy et al. [64] who found that individuals high in 'openness to experience' use the Internet more often but frequently engage in rather simple information retrieval tasks.

In contrast, control-related traits -especially CSE - are better predictors for Internet use intensity than for Internet use duration. The functionalities the Internet offers range in complexity. Whilst browsing and information seeking are rather simplistic, onlineshopping or online banking are more sophisticated. The more of these functionalities are applied, the more complex becomes using the Internet demanding requiring higher levels of being in 'control'.

In sum, our research gives initial evidence that research should be aware of the nature of these ITrelated traits and their resulting consequences for usage. Prior research often investigated these traits from a trait-hierarchy perspective $[6,14,16]$ or with behavior theories such as Social Cognitive Theory [18]. We encourage further research to unravel novel mechanisms that go beyond current narrowed views that explain how these factors evolve and which consequences can follow. The conceptualization of 'curiosity' and 'control' might pose novel directions for research on post-acceptance behavior [65]. For instance, literature on the psychology of curiosity [46] notes the 'tendency to disappoint when satisfied' 
as a consequence of curiosity and might serve as interesting perspective on discontinued IT use.

Moreover, our research contributes to our understanding on individual differences in postacceptance behavior specifically targeted on mature adults, which have been frequently denoted as 'digital immigrants'. Literature often assumes that this group tends to resist accepting technologies and only recently preliminary evidence started to evolve indicating that these adults are more heterogeneous in their technology behavior than often assumed [1]. However, although anxieties and self-efficacy perceptions have been reported frequently to determine mature adults technology behavior $[1,13]$ we extended this research by incorporating two additional important factors, Personal Innovativeness in IT and Computer Playfulness. We thereby provide a richer understanding in which facets mature adults differ and how these differentiators predict variations in two distinct Internet use forms.

\subsection{Practical implications}

This research has important practical implications for technology managers and system designers who seek to understand the characteristics of the growing segment of mature adults. Our research suggests that practice should pay attention to these curiosity- and control-related differences when designing and promoting systems for the target group.

The results show that mature adults who are higher in curiosity tend to engage longer in Internet use. Thus, if practice wants their audience to spend longer time with the technology provided, they need to incorporate curiosity-stimulating mechanisms, such as audio-visual content. If the extent of used features is regarded as a proxy for success or when features are included that are of higher complexity, then the self-perceptions of mature adult's abilities in using technologies have to be taken into account, specifically when their computer self-efficacy is rather low. Low beliefs in their own abilities have been shown to influence their ease-of-use perceptions and applications should be designed in a way that mature adults have the feeling of being in control of it. Another approach is to provide dedicated training and other support mechanisms to increase confidence to successfully utilize features of Internet applications [13].

\subsection{Limitations}

The following limitations must be taken into account when interpreting the results. First, our study targeted mature adults aged 50 and above. This age threshold is not undisputed in in published research. Second, since our technology under investigation was the Internet, we adapted the measurements to the Internet context and limiting our results to the context of the Internet. Third, we build upon self-reported usage that was measured at one time. Although such measures have been frequently employed in prior research, they are not without criticism [10].

\section{Conclusion}

Our research explains differences in Internet Use of mature adults aged 50 and above. Often denoted as 'digital immigrants', prior literature frequently claimed that this group poses resistance and difficulties in accepting technologies thereby leaving the Internet underutilized and functionalities that enhance various quality of life aspects untapped [1]. Recent evidence, however, suggests that adults are more heterogeneous in their technology behavior than often assumed [1].

In order to unravel factors that account for these differences we used established IT-related traits as potential predictors $[6,16]$ and conceptualized these as curiosity- and control-related factors.

Based on data of 135 informants aged 50 and above we show that IT-related traits predict different types of Internet use (defined as duration and intensity of use) of mature adults. Curiosity-related traits -Personal Innovativeness in IT and Computer Playfulness-account for variations in time spent online, whereas control-related traits -Computer Self-Efficacy and Computer Anxiety-predict the intensity of Internet use or the purposes for which the Internet is used for.

\section{Acknowledgment}

This research received funding from the German Federal Ministry of Education and Research (BMBF) under grant code 01FR14021 / 02K12B033. The responsibility for the content lies with the authors.

\section{References}

[1] Niehaves, B., and R. Plattfaut, "Internet adoption by the elderly: employing IS technology acceptance theories for understanding the age-related digital divide", European Journal of Information Systems, 23(6), 2014, pp. 708-726.

[2] Wang, Q.E., M.D. Myers, and D. Sundaram, "Digital Natives and Digital Immigrants", Business \& Information Systems Engineering, 5(6), 2013, pp. 409-419.

[3] Vodanovich, S., D. Sundaram, and M. Myers, "Research commentary-Digital natives and ubiquitous 
information systems", Information Systems Research, 21(4), 2010, pp. 711-723.

[4] Agarwal, R., and J. Prasad, "Are Individual Differences Germane to the Acceptance of New Information Technologies?", Decision Sciences, 30(2), 1999, pp. 361391.

[5] Tams, S., V. Grover, and J. Thatcher, "Modern information technology in an old workforce: Toward a strategic research agenda", The Journal of Strategic Information Systems, 23(4), 2014, pp. 284-304.

[6] Maier, C., "Personality within Information Systems Research: A Literature Analysis", in: Proceedings of the 28th European Conference on Information Systems, 2012

[7] Bitkom, "Senioren in der digitalen Welt", http://www.bitkom.org/files/documents/BITKOM-

Praesentation_Senioren_in_der_Digitalen_Welt_12_12_20

14.pdf, accessed February 02, 2015.

[8] Anderson, M., and A. Perrin, "Tech Adoption Climbs Among Older Adults", http://www.pewinternet.org/2017/05/17/technology-useamong-seniors/, accessed August 17, 2017.

[9] Smith, A., "Older adults and technology use", http://www.pewinternet.org/2014/04/03/older-adults-andtechnology-use/, accessed August 17, 2017.

[10] Burton-Jones, A., and D.W.J. Straub, "Reconceptualizing system usage: An approach and empirical test", Information Systems Research, 17(3), 2006, pp. 228-246.

[11] Venkatesh, V., S.A. Brown, L.M. Maruping, and H. Bala, "Predicting different conceptualizations of system use: the competing roles of behavioral intention, facilitating conditions, and behavioral expectation", MIS Quarterly, 32(3), 2008, pp. 483-502.

[12] Lallmahomed, M.Z., N.Z.A. Rahim, R. Ibrahim, and A.A. Rahman, "Predicting different conceptualizations of system use: Acceptance in hedonic volitional context (Facebook)", Computers in Human Behavior, 29(6), 2013, pp. 2776-2787.

[13] Lam, J.C.Y., and M.K.O. Lee, "Digital InclusivenessLongitudinal Study of Internet Adoption by Older Adults", Journal of Management Information Systems, 23(4), 2006, pp. 177-206.

[14] Davis, J.M., and Y.Y. Mun, "User disposition and extent of Web utilization: A trait hierarchy approach", International Journal of Human-Computer Studies, 70(5), 2012, pp. 346-363.

[15] Agarwal, R., "Individual Acceptance of New Information Technologies", in: Framing the Domains of IT Management Research: Glimpsing the Future through the Past (Zmud, R.W., 'ed.' Pinnaflex, Cincinnati, OH, 2000, pp. 85-104.

[16] Thatcher, J.B., and P.L. Perrewe, "An empirical examination of individual traits as antecedents to computer anxiety and computer self-efficacy", MIS Quarterly, 26(4), 2002, pp. 381-396.

[17] Bandura, A., Self-Efficacy: The Exercise of Control, Freeman, New York, 1997.

[18] Compeau, D., C.A. Higgins, and S. Huff, "Social cognitive theory and individual reactions to computing technology: A longitudinal study", MIS Quarterly, 23(2), 1999, pp. 145-158.
[19] Rogers, E.M., Diffusion of Innovations, The Free Press, First edn, New York, 1962.

[20] Moore, G.C., and I. Benbasat, "Development of an instrument to measure the perceptions of adopting an information technology innovation", Information systems research, 2(3), 1991, pp. 192-222.

[21] Webster, J., and J.J. Martocchio, "Microcomputer playfulness: development of a measure with workplace implications", MIS quarterly, 1992, pp. 201-226.

[22] Csikszentmihalyi, M., Flow: The Psychology of Optimal Experience, Harper and Row, New York, NY, 1990.

[23] Venkatesh, V., "Determinants of perceived ease of use: Integrating control, intrinsic motivation, and emotion into the technology acceptance model", Information Systems Research, 11(4), 2000, pp. 342-365.

[24] Hackbarth, G., V. Grover, and Y.Y. Mun, "Computer playfulness and anxiety: positive and negative mediators of the system experience effect on perceived ease of use", Information \& management, 40(3), 2003, pp. 221-232.

[25] Agarwal, R., and E. Karahanna, "Time flies when you're having fun: Cognitive absorption and beliefs about information technology usage", MIS quarterly, 2000, pp. 665-694.

[26] Agarwal, R., and J. Prasad, "A conceptual and operational definition of personal innovativeness in the domain of information technology", Information Systems Research, 9(2), 1998, pp. 204-215.

[27] Powell, A.L., "Computer anxiety: Comparison of research from the 1990s and 2000s", Computers in Human Behavior, 29(6), 2013, pp. 2337-2381.

[28] Hurt, H.T., K. Joseph, and C.D. Cook, "Scales for the measurement of innovativeness", Human Communication Research, 4(1), 1977, pp. 58-65.

[29] Yi, M.Y., K.D. Fiedler, and J.S. Park, "Understanding the Role of Individual Innovativeness in the Acceptance of IT-Based Innovations: Comparative Analyses of Models and Measures*", Decision Sciences, 37(3), 2006, pp. 393426.

[30] Jackson, J.D., Y.Y. Mun, and J.S. Park, "An empirical test of three mediation models for the relationship between personal innovativeness and user acceptance of technology", Information \& Management, 50(4), 2013, pp. $154-161$.

[31] Wang, W., X. Li, and J.P.-A. Hsieh, "The contingent effect of personal IT innovativeness and IT self-efficacy on innovative use of complex IT", Behaviour \& Information Technology, 32(11), 2013, pp. 1105-1124.

[32] Magni, M., L. Maruping, L. Caporarello, and S. Basaglia, "Innovating with technology in team contexts: a trait activation theory perspective", in: Proceedings of the International Conference on Information Systems, Year [33] Magni, M., M.S. Taylor, and V. Venkatesh, "'To play or not to play': A cross-temporal investigation using hedonic and instrumental perspectives to explain user intentions to explore a technology", International journal of human-computer studies, 68(9), 2010, pp. 572-588.

[34] Sun, H., "Understanding user revisions when using information system features: adaptive system use and triggers", Mis Quarterly, 36(2), 2012, pp. 453-478. 
[35] Compeau, D.R., and C.A. Higgins, "Computer selfefficacy: Development of a measure and initial test", MIS Quarterly, 19(2), 1995, pp. 189-211.

[36] Ajzen, I., "Perceived Behavioral Control, SelfEfficacy, Locus of Control, and the Theory of Planned Behavior1", Journal of Applied Social Psychology, 32(4), 2002, pp. 665-683.

[37] Venkatesh, V., M.G. Morris, G.B. Davis, and F.D. Davis, "User Acceptance of Information Technology: Toward a Unified View", MIS Quarterly, 27(3), 2003, pp. 425-478.

[38] Vijayasarathy, L.R., "Predicting consumer intentions to use on-line shopping: the case for an augmented technology acceptance model", Information \& Management, 41(6), 2004, pp. 747-762.

[39] Hsieh, J.P.-A., A. Rai, and M. Keil, "Understanding digital inequality: Comparing continued use behavioral models of the socio-economically advantaged and disadvantaged", MIS quarterly, 2008, pp. 97-126.

[40] Heinssen, R.K., C.R. Glass, and L.A. Knight, "Assessing Computer Anxiety: Development and Validation of the Computer Anxiety Rating Scale", Computers in Human Behavior, 3(1987, pp. 49-59.

[41] Parasuraman, S., and M. Igbaria, "An examination of gender differences in the determinants of computer anxiety and attitudes toward microcomputers among managers", International Journal of Man-Machine Studies, 32(3), 1990, pp. 327-340.

[42] Marakas, G.M., R.D. Johnson, and J.W. Palmer, "A theoretical model of differential social attributions toward computing technology: when the metaphor becomes the model", International Journal of Human-Computer Studies, 52(4), 2000, pp. 719-750.

[43] Nimrod, G., "Older audiences in the digital media environment", Information, Communication \& Society, 2016, pp. 1-17.

[44] Ajzen, I., "From intentions to actions: A theory of planned behavior", in: Action Control: From Cognition to Behavior (Kuhl , J., and Beckmann, J., 'eds.'), Springer, New York, 1985, pp. 11-39.

[45] Maier, C., S. Laumer, and A. Eckhardt, "Technology adoption by elderly people-an empirical analysis of adopters and non-adopters of social networking sites", in: Theory-Guided Modeling and Empiricism in Information Systems Research, Springer, 2011, pp. 85-110.

[46] Loewenstein, G., "The psychology of curiosity: A review and reinterpretation", Psychological bulletin, 116(1), 1994, p 75.

[47] Schneider, A., G. Von Krogh, and P. Jäger, "“What's coming next?" Epistemic curiosity and lurking behavior in online communities", Computers in Human Behavior, 29(1), 2013, pp. 293-303.

[48] Berlyne, D.E., "A theory of human curiosity", British Journal of Psychology, 45(3), 1954, pp. 180-191.

[49] Oehlhorn, C., C. Maier, J. Wirth, S. Laumer, and S. Dürr, "A Temptation to Stalk: The Impact of Curiosity on User Acceptance of Social Networking Sites", in: Proceedings of the Americas Conference on Information Systems, 2016
[50] Malone, T.W., "Toward a theory of intrinsically motivating instruction*", Cognitive Science, 5(4), 1981, pp. 333-369.

[51] Ajzen, I., "The theory of planned behavior", Organizational behavior and human decision processes, 50(2), 1991, pp. 179-211.

[52] Jasperson, J.S., P.E. Carter, and R.W. Zmud, "A Comprehensive Conceputalization of the Post-Adoptive Behaviors Associated with IT-Enabled Work Systems", MIS Quarterly, 29(3), 2005, pp. 525-557.

[53] Limayem, M., S.G. Hirt, and C.M. Cheung, "How habit limits the predictive power of intention: The case of information systems continuance", Mis Quarterly, 2007, pp. 705-737.

[54] Csikszentmihalyi, M., and J. Lefevre, "Optimal experience in work and leisure", Journal of personality and social psychology, 56(5), 1989, p 815.

[55] Webster, J., L.K. Trevino, and L. Ryan, "The Dimensionality and Correlates of Flow in HumanComputer Interactions", Computers in human behavior, 9(4), 1993, pp. 411-426.

[56] Bozoglan, B., V. Demirer, and I. Sahin, "Problematic Internet use: Functions of use, cognitive absorption, and depression", Computers in Human Behavior, 37(2014, pp. 117-123.

[57] Bandura, A., "Self-efficacy mechanism in human agency", American Psychologist, 37(2), 1982, pp. 122-147. [58] Davis, J., L. Lee, and M. Yi, "Examining the relationships among personality traits, IT-specific traits, and perceived ease of use", AMCIS 2007 Proceedings, 2007, p 295.

[59] Kim, Y., and M. Glassman, "Beyond search and communication: Development and validation of the Internet Self-efficacy Scale (ISS)", Computers in Human Behavior, 29(4), 2013, pp. 1421-1429.

[60] Venkatesh, V., and H. Bala, "Technology acceptance model 3 and a research agenda on interventions", Decision Sciences, 39(2), 2008, pp. 273-315.

[61] Ringle, C.M., S. Wende, and J.-M. Becker, "SmartPLS 3", SmartPLS GmbH, Boenningstedt, 2015

[62] Chin, W.W., "The partial least squares approach to structural equation modeling", Modern methods for business research, 295(2), 1998, pp. 295-336.

[63] Fornell, C., and D.F. Larcker, "Evaluating structural equation models with unobservable variables and measurement error", Journal of Marketing Research, 1981, pp. 39-50.

[64] Mcelroy, J.C., A.R. Hendrickson, A.M. Townsend, and S.M. Demarie, "Dispositional factors in internet use: personality versus cognitive style", MIS Quarterly, 2007, pp. 809-820.

[65] Bhattacherjee, A., "Understanding Information Systems Continuance: An Expectation-Confirmation Model", MIS Quarterly, 25(3), 2001, pp. 351-370. 